TITLE:

\title{
Preparation of polymer-based magnetic resonance imaging contrast agent to visualize therapeutic angiogenesis.
}

\section{$\operatorname{AUTHOR}(\mathrm{S}):$}

Jo, Jun-Ichiro; Lin, Xue; Nakahara, Teppei; Aoki, Ichio; Saga, Tsuneo; Tabata, Yasuhiko

\section{CITATION:}

Jo, Jun-Ichiro ...[et al]. Preparation of polymer-based magnetic resonance imaging contrast agent to visualize therapeutic angiogenesis.. Tissue engineering. Part A 2012, 19(1-2): 30-39

ISSUE DATE:

2012-12

URL:

http://hdl.handle.net/2433/168521

\section{RIGHT:}

This is a copy of an article published in the Tissue Engineering Part A.; (c)2012 Mary Ann Liebert, Inc.; "Tissue Engineering Part A" is available online at: http://online.liebertpub.com. 


\title{
Preparation of Polymer-Based Magnetic Resonance Imaging Contrast Agent to Visualize Therapeutic Angiogenesis
}

\author{
Jun-ichiro Jo, Ph.D., ${ }^{1,2}$ Xue Lin, M.D., Ph.D.,, ${ }^{1}$ Teppei Nakahara, M.Sci., ${ }^{2}$ Ichio Aoki, Ph.D., ${ }^{2}$ \\ Tsuneo Saga, M.D., Ph.D., ${ }^{2}$ and Yasuhiko Tabata, Ph.D., D.Med.Sci., D.Pharm. ${ }^{1}$
}

The objective of this study was to design and prepare a new contrast agent of magnetic resonance (MR) imaging for the evaluation of therapeutic angiogenesis. Diethylenetriaminepentaacetic acid (DTPA) residue of a chelator was chemically introduced to dextran with a molecular weight of 74,000 (dextran-DTPA). Cyclic peptide containing an arginine-glycine-aspartic acid (RGD) sequence (cyclic RGD) with an inherent affinity for the $\alpha_{v} \beta_{3}$ integrin was then introduced to dextran-DTPA (Cyclic RGD-dextran-DTPA). Gd $^{3+}$ was added to cyclic RGDdextran-DTPA to prepare a dextran-based MR contrast agent (Cyclic RGD-dextran-DTPA-Gd). Cyclic RGDdextran-DTPA-Gd had affinity for cells expressing the $\alpha_{v} \beta_{3}$ integrin and showed a higher longitudinal relaxivity compared with DTPA-Gd of an MR contrast agent clinically used. Right femoral, external iliac, and deep femoral and circumflex arteries and veins were surgically ligated to prepare a mouse model of hindlimb ischemia. A laser Doppler analysis and histological evaluation confirmed that hindlimb ischemia healed naturally and was accompanied by angiogenesis, while $\alpha_{v} \beta_{3}$ integrin was expressed in the ischemic-angiogenic region without any treatment. Mice at 7 days after vascular ligation were used as an angiogenesis model. When intravenously injected into mice with hindlimb ischemia, cyclic RGD-dextran-DTPA accumulated in the ischemic-angiogenic region and showed the MR ability to detect the ischemic-angiogenic region. It is concluded that cyclic RGDdextran-DTPA-Gd is a promising material for evaluation of therapeutic angiogenesis.

\section{Introduction}

W ITH THE RECENT PROGRESS IN molecular and cellular biology, as well as tissue engineering, it has become practically possible to treat diseases based on the naturalhealing potential of patients themselves. This is called regenerative medicine and has been expected as a new field of medical treatment. Some animal and clinical trials have been successfully performed to regenerate and repair injured or defective tissues, such as bone, cartilage, skin, and nerve tissues by making use of cells and biomaterials as drug delivery systems (DDS) of growth factors and cell scaffolds. ${ }^{1-6}$ However, the technology and methodology used to evaluate the extent and process of tissue regeneration and repairing still depend on conventional diagnostic methods such as histological, ${ }^{7}$ biochemical, ${ }^{8}$ and morphological examinations. ${ }^{9}$ The clinical availability of these examinations is limited in terms of their invasiveness and reliability. Under these circumstances, it is necessary to develop a new diagnosis system for the noninvasive evaluation of tissue regeneration.

Molecular imaging is defined as the in vivo visualization of spatiotemporal distribution of molecular biological processes in the cell and tissue of interest. ${ }^{10,11}$ There is no doubt that the technology of molecular imaging plays an important role in the noninvasive evaluation of tissue regeneration. Molecular imaging includes the imaging probes and the corresponding imaging modality. So far, various types of imaging probe have been reported, such as $\mathrm{Gd}^{3+}$ and manganese ion $\mathrm{Mn}^{2+},{ }^{19} \mathrm{~F}$, and iron oxide nanoparticles for magnetic resonance imaging $(\mathrm{MRI}),{ }^{12,13}$ radioisotopes $\left({ }^{99 \mathrm{~m}} \mathrm{Tc},{ }^{111} \mathrm{In},{ }^{123} \mathrm{I}\right.$, ${ }^{18} \mathrm{~F},{ }^{64} \mathrm{Cu}$, and $\left.{ }^{124} \mathrm{I}\right)$ or their derivatives for positron emission tomography (PET) $)^{14,15}$ and single photon emission computed tomography (SPECT) ${ }^{16-18}$ luciferase and $\beta$-galactosidase for bio-luminescence imaging, ${ }^{19,20}$ and quantum dots and nearinfrared fluorescent (NIRF) dyes for fluorescence imaging. ${ }^{21,22}$ To maximize the efficacy of molecular imaging, DDS technologies contribute by increasing in the signal-to-noise ratio of the target tissue. It has been demonstrated that combination with nano-sized carriers, such as water-soluble polymers, polymer micelles, emulsions, and liposomes, enables imaging probes that simultaneously condense and are stably carried in the blood circulation, resulting in enhanced imaging efficacy. ${ }^{23,24}$ Furthermore, modification with targeting moietes such as antibody enables nano-sized carriers to be actively delivered to the tissue of interest.

${ }^{1}$ Department of Biomaterials, Institute for Frontier Medical Sciences, Kyoto University, Kyoto, Japan.

${ }^{2}$ Diagnostic Imaging Program, Molecular Imaging Center, National Institute of Radiological Sciences, Chiba, Japan. 
Angiogenesis is defined as the formation of capillaries from existing vessels and is a fundamental process that is involved in various phenomena, including development, wound healing, tissue regeneration (physiological angiogenesis), and progression of chronic inflammation and tumor (pathological angiogenesis). ${ }^{25}$ Angiogenesis occurs via several processes: (1) the degradation of extracellular matrix surrounding the existing vasculature; (2) the proliferation and migration of endothelial cells thereat as well as the attraction of blood-derived macrophages and circulating stem cells; and (3) the integration of endothelial cells, followed by tube formation. ${ }^{26,27}$ Many reports have been focused on the tumor angiogenesis imaging. ${ }^{28}$ The hypoxia-inducible factor$1 \alpha^{29,30}$ vascular endothelial growth factor (VEGF), ${ }^{31-33}$ matrix metalloproteinase, ${ }^{34,35}$ and $\alpha_{v} \beta_{3}$ integrin $^{32,36,37}$ have been used as a molecule of interest. On the other hand, the angiogenic therapies against the ischemic disease have been actively developed and performed. ${ }^{38}$ However, there are a few research reports ${ }^{39-42}$ regarding the molecular imaging for "therapeutic" angiogenesis. It is quite important to develop technologies and methodologies for accurately determining therapeutic effects.

In this study, an MRI contrast agent linked to dextran was prepared to evaluate the angiogenic process. A cyclic peptide containing an arginine-glycine-aspartic acid (RGD) sequence (cyclic RGD) with an inherent affinity for $\alpha_{v} \beta_{3}$ integrin activated during the proliferation and migration of endothelial cells $^{43,44}$ and diethylenetriaminepentaacetic acid (DTPA) residues for chelation of $\mathrm{Gd}^{3+}$ were chemically introduced to dextran. The affinity of the dextran-based MRI agent for cells expressing the $\alpha_{v} \beta_{3}$ integrin receptor was investigated, while angiogenic imaging efficacy was evaluated in a mouse model of hindlimb ischemia.

\section{Materials and Methods}

\section{Materials}

Dextran with a weight-averaged molecular weight of 74,000, DTPA anhydride, and gadolinium chloride were purchased from Sigma Chemical Co., St. Louis, MO. A cyclic peptide with the sequence of ACRGDMFGCA (Cyclic RGD) ${ }^{45,46}$ was obtained from Activotec, Cambridge, UK. Other chemicals were obtained from Nacalai Tesque, Inc., Kyoto, Japan and used without further purification.

\section{Preparation of contrast agents (Fig. 1)}

First, DTPA anhydride (330 mg, $0.93 \mathrm{mmole}$ ) and 4dimethylaminopyridine $(16 \mathrm{mg}$ ) were added to $10 \mathrm{~mL}$ of dehydrated dimethyl sulfoxide containing $100 \mathrm{mg}$ (1.9 mmole of hydroxyl $[\mathrm{OH}]$ groups) of dextran. The reaction solution was agitated at room temperature for $18 \mathrm{~h}$ to introduce DTPA residues to the $\mathrm{OH}$ of dextran, followed by dialysis against double-distilled water (DDW) for 2 days, and freeze drying to obtain DTPA-introduced dextran (dextran-DTPA). The amount of DTPA residues introduced was measured by conventional conductometric titration. Next, cyclic RGD (11 mg, $11 \mu$ mole of amino groups) was added to dextranDTPA (50 mg, $210 \mu$ mole of carboxyl groups) in 2-morpholineoethanesulfate (MES)-buffered solution (0.1 M, $\mathrm{pH} 5.0$ ), followed by adding coupling agents of 1-ethyl-3-(3dimethylaminopropyl)-carbodiimide (EDC, $74 \mathrm{mg}, 630 \mu \mathrm{mole})$ and N-hydroxy succinimide (NHS, $120 \mathrm{mg}, 630 \mu \mathrm{mole})$. The reaction solution was agitated at room temperature for $3 \mathrm{~h}$ to introduce the amino groups of cyclic RGD to the carboxyl groups of dextran-DTPA, followed by dialysis against DDW for 2 days and freeze drying to obtain cyclic RGD-introduced

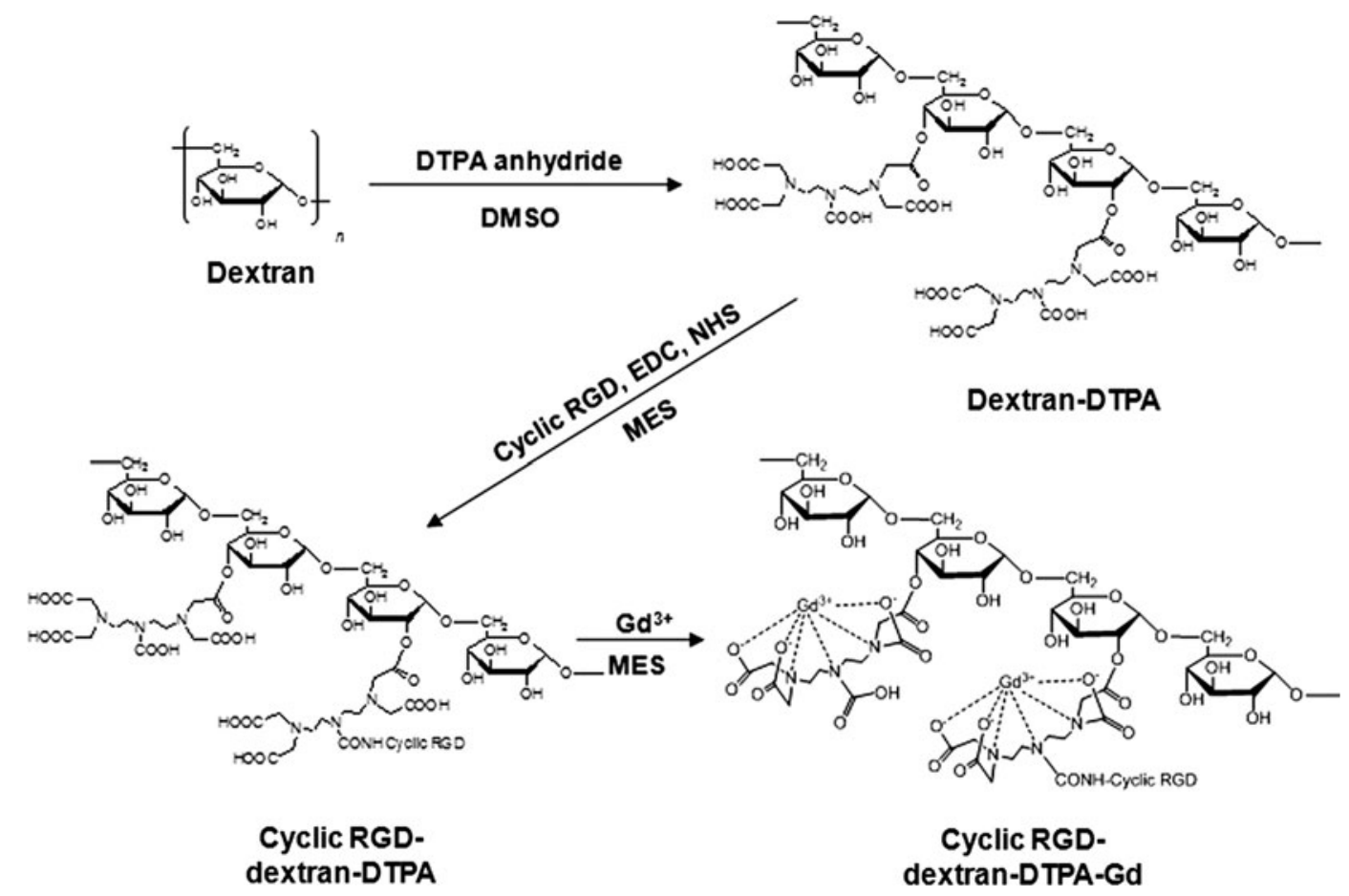

FIG. 1. Preparation procedure of cyclic RGD-dextran-DTPA-Gd. RGD, arginine-glycine-aspartic acid; DTPA-Gd, diethylenetriaminepentaacetic acid-gadolinium. EDC, 1-ethyl-3-(3-dimethylaminopropyl)-carbodiimide; NHS, N-hydroxy succinimide; MES, 2-morpho-lineoethanesulfate. 
dextran-DTPA (Cyclic RGD-dextran-DTPA). The amount of cyclic RGD introduced was measured by a trinitrobenzene sulfonic acid method. ${ }^{47}$ Finally, $0.2 \mathrm{~mL}$ of gadolinium chloride solution $(156 \mathrm{mg} / \mathrm{mL}, 84 \mu$ mole) was mixed with $1 \mathrm{~mL}$ of cyclic RGD-dextran-DTPA solution $(5 \mathrm{mg} / \mathrm{mL}, 8.4 \mu \mathrm{mole})$ in $0.1 \mathrm{M}$ MES-buffered solution ( $\mathrm{pH}$ 6.0). The mixtures were agitated at room temperature for $3 \mathrm{~h}$ to chelate $\mathrm{Gd}^{3+}$ to the DTPA residues. The reaction solution was purified by a PD-10 column (GE healthcare UK Ltd., Buckinghamshire, $\mathrm{UK}$ ) with DDW and freeze drying to obtain $\mathrm{Gd}^{3+}$-chelated cyclic RGD-dextran-DTPA (Cyclic RGD-dextran-DTPA-Gd). The amount of $\mathrm{Gd}^{3+}$ chelated was measured by an atomic absorption spectrophotometer (AA-6800, Shimadzu Corp., Kyoto, Japan). $\mathrm{Gd}^{3+}$-chelated dextran-DTPA (dextranDTPA-Gd) was also prepared as a control.

\section{In vitro evaluation of contrast agents}

5-([4,6-dichlorotriazin-2-yl]amino)fluorescein hydrochloride $(4 \mathrm{mg} / \mathrm{mL}, 500 \mu \mathrm{L}$; Sigma Chemical, Co.) was added to cyclic RGD-dextran-DTPA $(20 \mathrm{mg} / \mathrm{mL}, 500 \mu \mathrm{L})$. The solution $\mathrm{pH}$ was then adjusted to 10 by adding sodium hydroxide. ${ }^{48}$ The reaction solution was agitated at room temperature for $2 \mathrm{~h}$ and purified on a PD-10 column with DDW, followed by freeze drying to obtain fluorescein-labeled cyclic RGD-dextran-DTPA. Fluorescein-labeled dextran-DTPA was also prepared as a control.

Human umbilical vein endothelial cells (HUVEC; American Type Culture Collection, Manassas, VA) expressing $\alpha_{\mathrm{v}} \beta_{3}$ integrin were cultured at $37^{\circ} \mathrm{C}$ in a $95 \%$ air- $5 \%$ carbon dioxide atmosphere in an endothelial cell basal medium $\left(\mathrm{EBM}^{\circledR}\right)-2$ (Lanza, Walkersville, MD) supplemented with EGM $^{\circledR}-2$ SingleQuots ${ }^{\circledR}$ (Lanza) composed of human recombinant epidermal growth factor, heparin, hydrocortisone, fetal bovine serum ( $2 \mathrm{vol} \%$ ), human recombinant basic fibroblast growth factor, ascorbic acid, human recombinant VEGF, recombinant insulin-like growth factor-1, gentamycin sulfate $(50 \mathrm{mg} / \mathrm{mL})$, and amphotericin-B $(50 \mu \mathrm{g} / \mathrm{mL})$. The medium was changed after 3 days of culture and every 3 days thereafter. When proliferated in a sub-confluence condition, the cells were used for the following experiments.

HUVEC were seeded at the density of $2.0 \times 10^{5}$ cells / dish on $35 \mathrm{~mm}$ glass-bottom dishes (Matsunami Glass Ind., Ltd., Osaka, Japan) and cultured with $250 \mu \mathrm{g} / \mathrm{mL}$ of fluoresceinlabeled cyclic RGD-dextran-DTPA or dextran-DTPA. After $12 \mathrm{~h}$ of incubation, cells were washed with cold phosphatebuffered saline and fixed with $4 \mathrm{wt} \%$ paraformaldehyde for $30 \mathrm{~min}$. Cells nuclei were then stained with Hoechst 33342 (Molecular Probes, Inc., Eugene, OR). Imaging data for cells was collected on an Olympus Fluoview FV300 confocal laser scanning microscope (Olympus, Corp., Tokyo, Japan).

In vitro $\mathrm{MRI}$ acquisition of contrast agents was performed in a $7.0 \mathrm{~T}, 40 \mathrm{~cm}$ bore horizontal magnet (Kobelco and Jastec, Kobe, Japan) interfaced to a Bruker Avance console (Bruker Biospin, Ettlingen, Germany). A $72 \mathrm{~mm}$ diameter birdcage coil (transmission and reception; Bruker Biospin) was used for measurement of contrast agents. An aqueous solution of contrast agents with different $\mathrm{Gd}^{3+}$ ion concentrations $(150 \mu \mathrm{L})$ was placed into a polymerization chain reaction (PCR) tube $(200 \mu \mathrm{L})$ cluster plate (Simport Plastics Ltd., Beloeil, Canada). The PCR tube cluster plate was set in the center of the birdcage coil. Sample temperature was main- tained at room temperature $\left(\sim 19^{\circ} \mathrm{C}\right)$. The longitudinal relaxation time $\left(\mathrm{T}_{1}\right)$-weighted images were obtained using a conventional SE sequence with the following parameters: pulse repetition time $(\mathrm{TR})=400 \mathrm{~ms}$; echo time $(\mathrm{TE})=9.57 \mathrm{~ms}$; matrix size $=256 \times 256$; field of view $(\mathrm{FOV})=4.8 \times 4.8 \mathrm{~mm}$; slice thickness $(\mathrm{ST})=2.0 \mathrm{~mm}$; and number of acquisitions $(\mathrm{NA})=1$. The total acquisition time for three slices was $1.7 \mathrm{~min}$. Two-dimensional multi-slice saturation-recovery MRI was carried out using a rapid acquisition with relaxation enhancement (RARE) sequence for $\mathrm{T}_{1}$ map calculation with the following parameters: $\mathrm{TR}=500,750,1000,1500,3000$, and $5000 \mathrm{~ms}, \mathrm{TE}=2.2 \mathrm{~ms}$, matrix size $=256 \times 256, \mathrm{FOV}=4.8 \times 4.8$ $\mathrm{mm}^{2}, \mathrm{ST}=2.0 \mathrm{~mm}$, and $\mathrm{NA}=1$. Total acquisition time for saturation-recovery MRI was $9.5 \mathrm{~min}$. The longitudinal relaxivity $\left(R_{1}\right)$ was calculated by the following formula: $R_{1}=\left(1 / T_{1}\right.$ $\left.-1 / T_{0}\right) / C$, where $T_{0}$ is the longitudinal time of DDW, and $C$ is the corresponding $\mathrm{Gd}^{3+}$ concentration.

\section{Animal model}

Hindlimb ischemia was created in 6-week-old male C57BL/ 6 mice (Japan SLC, Inc., Shizuoka, Japan) to prepare a model of natural angiogenesis from ischemia. After the mice had been anesthetized with an intraperitoneal injection of sodium pentobarbital $(60 \mathrm{mg} / \mathrm{kg})$, the right groin area was shaved and prepped with povidone-iodine. The entire right saphenous artery and vein and the right external iliac artery and vein along with the deep femoral and circumflex arteries and veins were ligated, cut, and excised to obtain a model of severe hindlimb ischemia. To confirm the model preparation and natural healing through the angiogenesis, hindlimb blood perfusion $(n=4)$ was scanned by a laser Doppler perfusion image (LDPI) analyzer (Moor Instruments Ltd., Devon, UK) at 1 and 7 days after treatment. To eliminate the influence of the surgical procedure, the average blood perfusion in the bilateral feet was evaluated. To minimize influential variables including ambient light and temperature, perfusion was expressed as a percentage of the blood perfusion in the right (ischemic-angiogenic) limb to that in the left (normal) limb of the same mouse, that is, in terms of the LDPI index.

For histological examination in the ischemic-angiogenic region, mice $(n=3)$ treated 7 days earlier were euthanized and perfusion fixed with $4 \mathrm{wt} \%$ paraformaldehyde. Calf muscle tissues were then taken and washed several times with $20 \mathrm{wt} \%$ sucrose solution. Tissues were embedded in an optimal cutting temperature compound (Sakura Finetechnical, Co. Ltd., Tokyo, Japan) and frozen at $-80^{\circ} \mathrm{C}$. Cryostat serial sections ( $5 \mu \mathrm{m}$ thick) of tissues were created and separately stained with biotinylated endothelial-specific lectin (Bandeiraea simplicifolia lectin I, Vector Laboratories, Inc., Burlingame, CA) and rabbit anti-human integrin $\alpha_{\mathrm{v}}$ or $\beta_{3}$ polyclonal antibody $\left(\mathrm{CHEMICON}^{\circledR}\right.$ International, Inc., Temecula, CA) to confirm angiogenesis and integrin $\alpha_{\mathrm{v}} \beta_{3}$ expression, respectively. Biotinylated anti-rabbit IgG antibody (Vector Laboratories, Inc.) was used as a secondary antibody, and the points stained were visualized with Alexa FLUOR ${ }^{\circledR}$ 555-conjugated streptavidin (Molecular Probes, Inc.). Slides were mounted with Vector Shield (Vector Laboratories) containing 4',6-diamidino-2-phenylindole (DAPI) as a nucleus staining reagent. Imaging data were collected on the Olympus Fluoview FV300 confocal laser scanning microscope and processed with Adobe Photoshop 6.0 software 
(Adobe Systems, Inc., San Jose, CA). Microscopic fields on each slide were evaluated to calculate the ratio of integrin $\alpha_{\mathrm{v}}$ or $\beta_{3}$-positive cells to total cells.

\section{In vivo $M R$ imaging of ischemic-angiogenic region with cyclic RGD-dextran-DTPA-Gd}

In vivo MRI acquisition was performed in the 7T scanner. A $72 \mathrm{~mm}$ diameter birdcage coil (Bruker Biospin) and 2channel phased array coil (Rapid Biomedical GmbH, Rimpar, Germany) were used for transmission and reception, respectively. During MRI acquisition, mice were anesthetized with $2.0 \%$ isoflurane (Abbot Japan Co., Ltd., Tokyo, Japan). Rectal temperature was monitored continuously and maintained at $36.5^{\circ} \mathrm{C} \pm 0.5^{\circ} \mathrm{C}$ using a heating pad. A 30-gauge syringe needle connected to $1.0 \mathrm{~m}$ of polyethylene tubing (PE-10; Becton, Dickinson, and Co., Franklin Lakes, NJ) was inserted into the tail vein of mice $(n=5$ each) with hindlimb ischemia and fixed. The other side of the polyethylene tubing was connected to a $1.0 \mathrm{~mL}$ syringe for administration of the contrast agent. Mice were moved and placed in a prone position on a cradle. Anesthesia was given to the mice through a homemade face mask. The mouse hindlimb region was set in the center of the birdcage coil. Dextran-DTPA-Gd conjugated with or without cyclic RGD $(200 \mu \mathrm{L}$; Gd concentration $=5 \mathrm{mM}$ ) was intravenously injected to the mice through the polyethylene tubing line. MRI scans were performed before and at $0.5,1,2$, and $4 \mathrm{~h}$ after injection. Twodimensional $\mathrm{T}_{1}$-weighted multi-slice spin echo MRI with fat suppression was performed in the following parameters: $\mathrm{TR}=9.57 \mathrm{~ms}, \mathrm{TE}=250 \mathrm{~ms}$, matrix size $=256 \times 256, \mathrm{FOV}=3.2$ $\times 3.2 \mathrm{~mm}^{2}, \mathrm{ST}=1.0 \mathrm{~mm}$, and $\mathrm{NA}=16$. Slice orientation was horizontal (eight slices, nongap).

Image reconstruction and analysis was performed using ParaVision (version 5.0; Bruker Biospin) and MRVision (version 1.6.8, MRVision Co., Winchester, MA). Regions of interest (ROI) were set around the ischemic-angiogenic and normal regions of the hindlimb. At each imaging time, signal intensities from five ROI for each region were measured and recorded. Normalized signal ratios were calculated by dividing the signal intensity at each imaging time by that before the injection.

\section{Accumulation of cyclic RGD-dextran-DTPA in angiogenic region}

To investigate the accumulation extent of cyclic RGDdextran-DTPA in the ischemic-angiogenic region after intravenous injection, cyclic RGD-dextran DTPA was radiolabeled. Briefly, $10 \mu \mathrm{L}(3.2 \mathrm{MBq})$ of ${ }^{59} \mathrm{FeCl}_{3}$ (PerkinElmer, Inc., San Jose, CA) was added to $500 \mu \mathrm{L}$ of cyclic RGDdextran DTPA $(5 \mathrm{mg} / \mathrm{mL})$ in $0.1 \mathrm{M}$ MES-buffered solution ( $\mathrm{pH}$ 6.0), followed by agitation at room temperature for $3 \mathrm{~h}$. The reaction solution was purified on a PD-10 column with DDW to obtain ${ }^{59} \mathrm{Fe}$-chelated cyclic RGD-dextran-DTPA (cyclic RGD-dextran-DTPA-Fe). Cyclic RGD-dextran-DTPAFe $(200 \mu \mathrm{L})$ was intravenously injected to mice $(n=3)$ with hindlimb ischemia treated 7 days before. After $4 \mathrm{~h}$, the mice were sacrificed, and radioactivity of hindlimb ischemicangiogenic and normal regions was measured with a $\gamma$-counter (ARC-301B, Aloka Co. Ltd., Tokyo, Japan). ${ }^{59} \mathrm{Fe}$-chelated dextran-DTPA was used as a control.
A A
Cyclic RGD-
dextran-DTPA

Dextran-DTPA
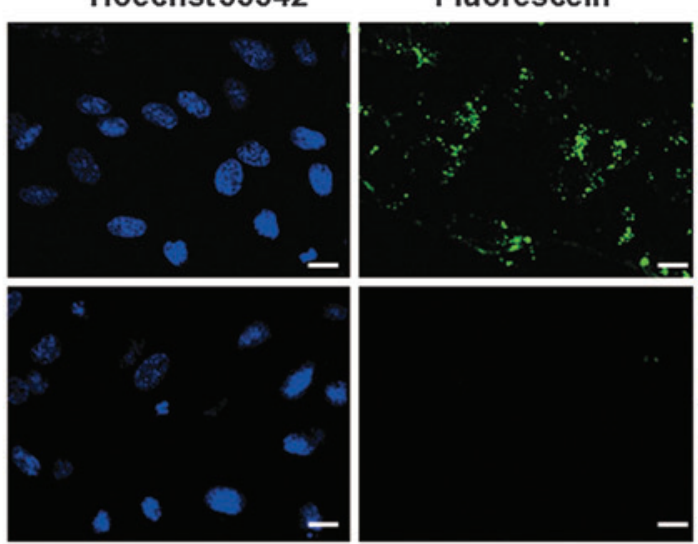

B

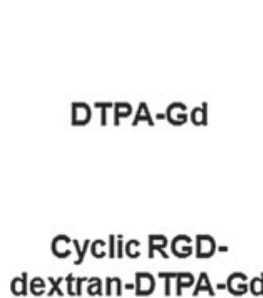
dextran-DTPA-Gd

Dextran-DTPA-Gd
Gd concentration (mM)

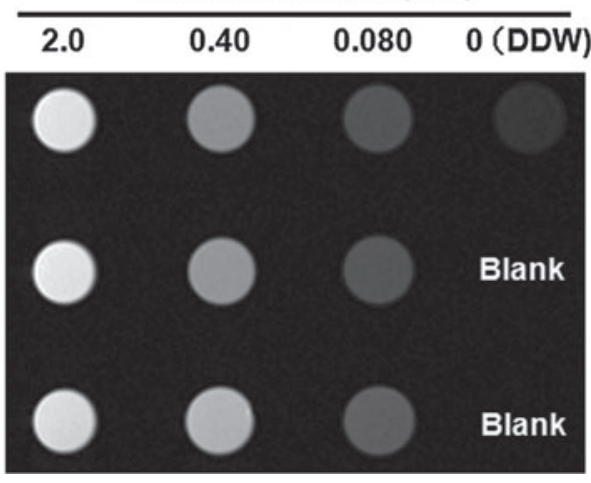

\section{Merged}
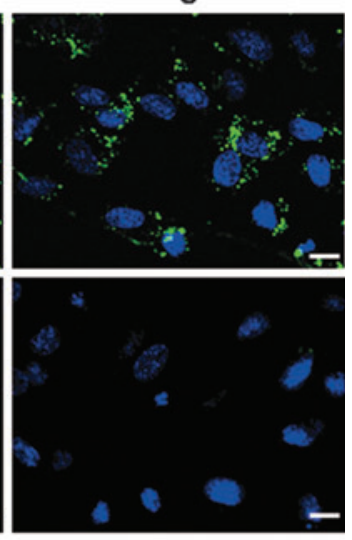

\section{Relaxivity}

$\left(\mathrm{s}^{-1} \mathrm{mM}^{-1}\right)$

$4.7+/-0.2$

$5.3+/-0.1$
FIG. 2. (A) Cellular internalization image of fluorescein-labeled cyclic RGD-dextran-DTPA or dextran-DTPA (green) after $12 \mathrm{~h}$ of incubation with HUVEC. Nuclei of HUVEC were stained with Hoechst 33342 (blue). Scale bar is $20 \mu \mathrm{m}$. (B) $\mathrm{T}_{1}$-weighted images and relaxivities of various contrast agents at different concentrations. The number of Gd molecules in the cyclic RGD-dextran DTPA and dextran-DTPA was 25 and 33, respectively. HUVEC, human umbilical vein endothelial cells. Color images available online at www.liebertpub.com/tea 
FIG. 3. (A) Representative images of hindlimb blood perfusion of mice 1 day and 7 days after ischemia creation. Mice were placed in the supine position and scanned by the laser-Doppler image analyzer. The left side shows the ischemic hindlimb. (B) Quantitative analysis of hindlimb blood perfusion of mice 1 and 7 days after ischemia creation. ${ }^{*} p<0.05$; significant against the laser Doppler perfusion image index (LDII) 1 day after ischemia creation. (C) Histological evaluation of angiogenesis in the ischemic-angiogenic or normal tissue of mice hindlimb 7 days after ischemia creation. Tissues were stained with Bandeiraea simplicifolia lectin I (red). Nuclei were stained with DAPI (blue). The Scale bar is $50 \mu \mathrm{m}$. DAPI, 4',6-diamidino-2phenylindole. Color images available online at www.liebertpub.com/tea
A

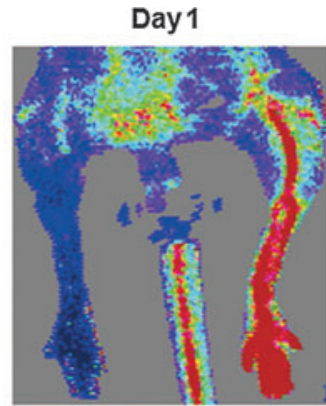

Ischemic- Normal angiogenic
Day 7

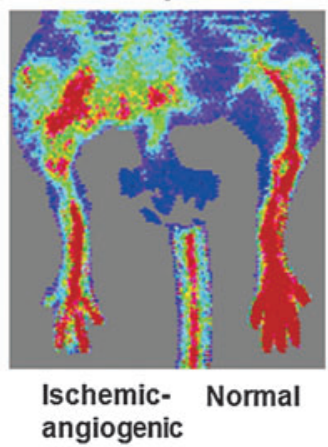

angiogenic

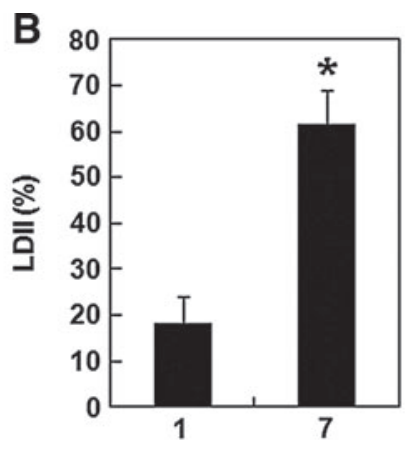

Time after ischemia creation (Day)

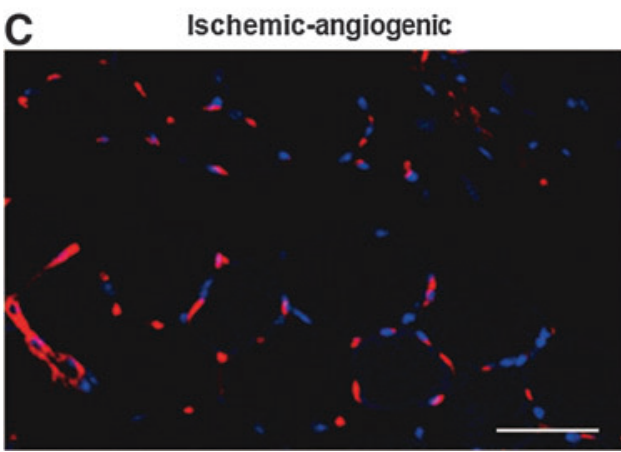

Normal

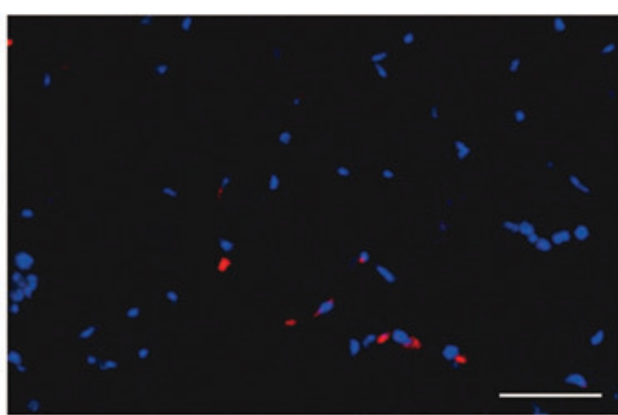

normal tissue of mice

hindlimb 7 days after ischemia creation. Tissues were stained with each integrin $\alpha_{\mathrm{v}}$ and $\beta_{3}$ (red). Nuclei were stained with DAPI (blue). Scale bar is $50 \mu \mathrm{m}$. (B) Quantitative analysis of integrin $\alpha_{\mathrm{v}} \beta_{3}$ expression in the ischemicangiogenic or normal tissue of mice hindlimb 7 days after ischemia creation. Integrin $\alpha_{v}-$ or $\beta_{3}$-positive cells in each cell image were counted, and the percentage versus total cells was calculated. Color images available online at www.liebertpub.com/tea

A
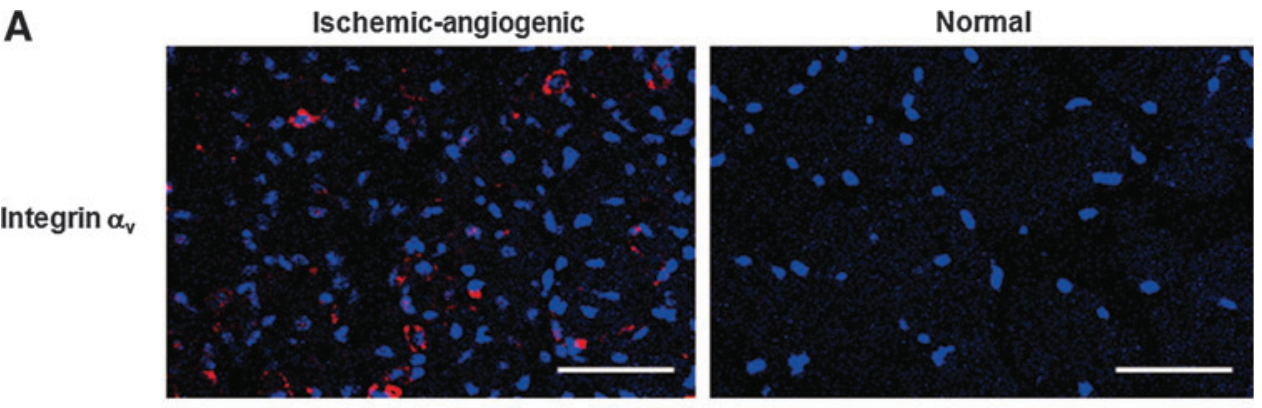

Integrin $\beta_{3}$
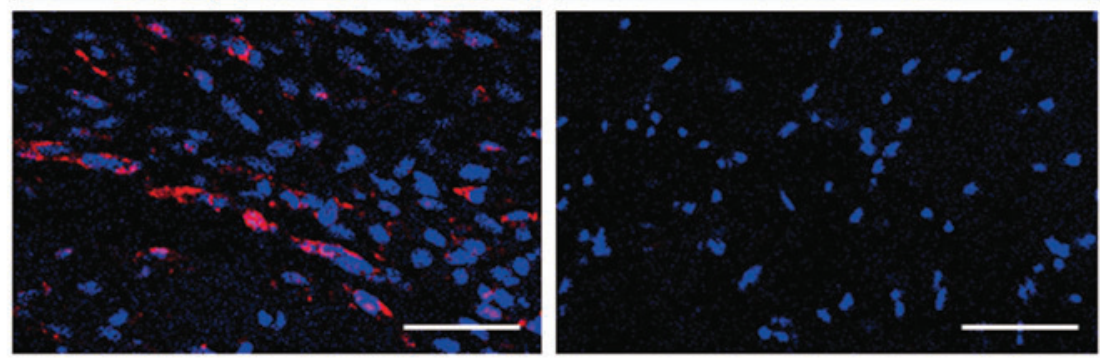

B

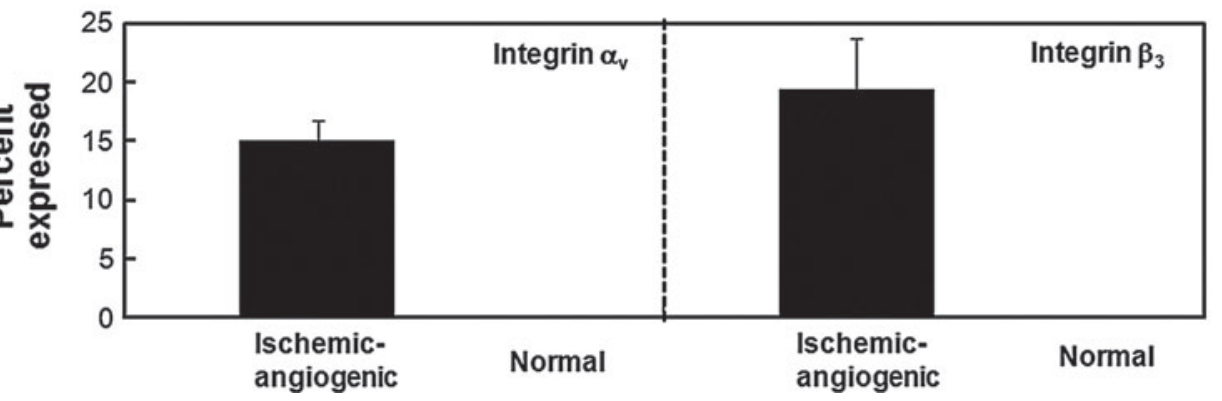


A
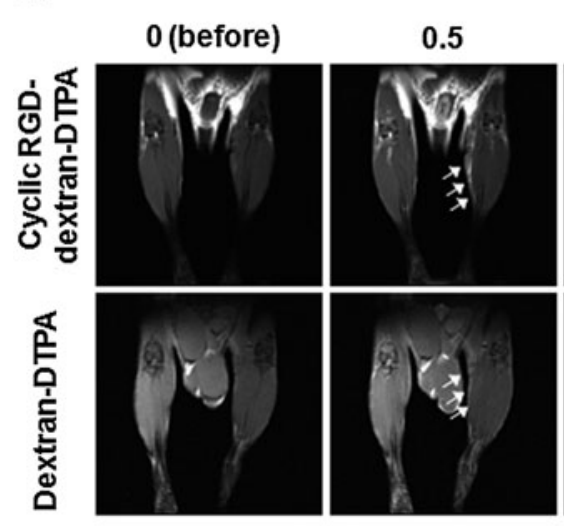

Time after injection (hr)
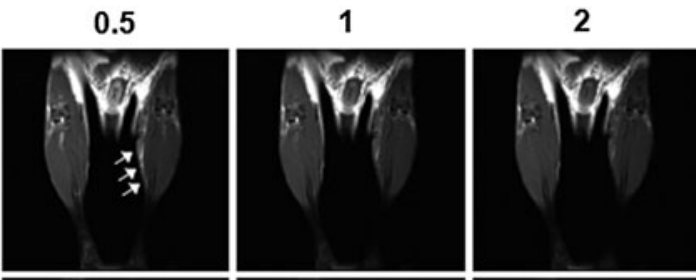
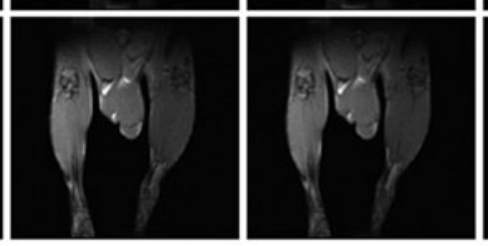

B

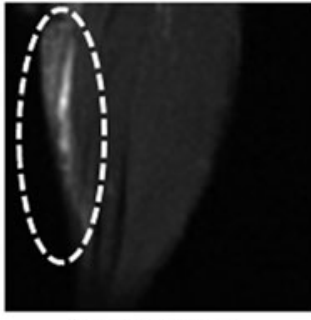

Cyclic RGDdextran-DTPA

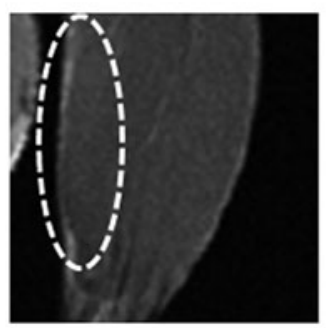

Dextran-DTPA

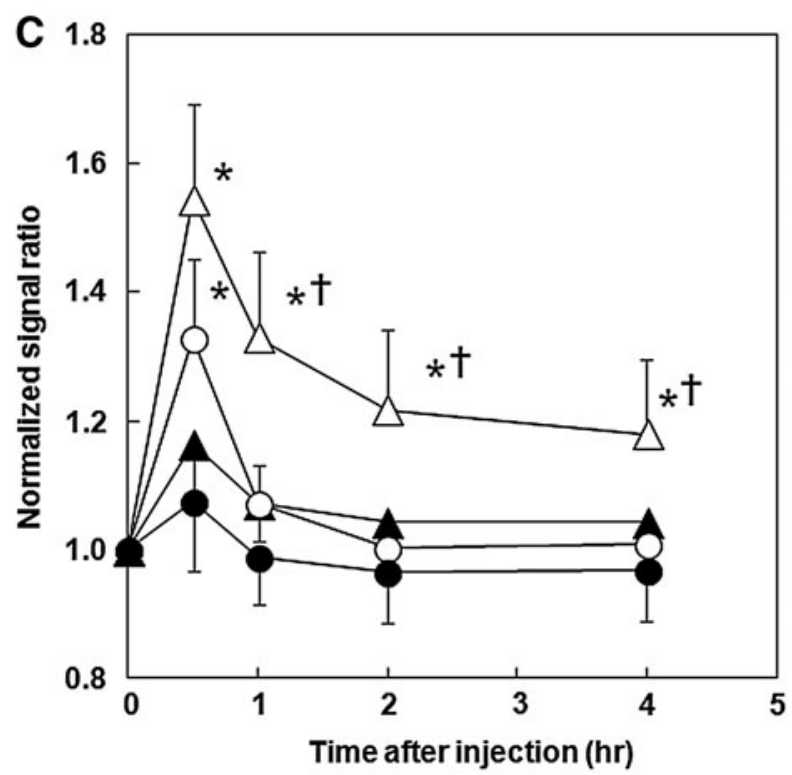

FIG. 5. (A) Representative magnetic resonance images of mice hindlimb region before and after an injection of dextran-DTPA-Gd or cyclic RGD-dextran-DTPAGd. Mice were placed in the supine position. The right side shows the ischemic hindlimb. Arrows indicate the ischemic-angiogenic region. (B) Representative enlarged image of ischemicangiogenic region (dashed ellipses). (C) Time profiles of $\mathrm{T}_{1}$ signal intensity ratio in the mice hindlimb after injection of dextran-DTPA-Gd $(O, \mathbf{0})$ or cyclic RGD-dextranDTPA-Gd $(\triangle, \mathbf{\Delta})$. Signals (five points each) were acquired in normal (solid) and ischemic-angiogenic region (open). Hindlimb ischemia (five mice each) was created 7 days before the injection. $\mathrm{Gd}^{3+}$ concentration of the contrast agent is $5.0 \mathrm{mM}$. ${ }^{*} p<0.05$; significant against the normalized signal ratio in the normal region after the injection of corresponding agent at the corresponding time. ${ }^{\dagger} p<0.05$; significant against the normalized signal ratio in the ischemic-angiogenic region after injection of dextranDTPA-Gd at the corresponding time.

\section{Statistical analysis}

Data are expressed as means \pm standard deviation. Data were analyzed using a Tukey-Kramer paired comparison test, while the significance was set at $p<0.05$.

\section{Results}

\section{Preparation of contrast agents}

The dextran-based contrast agent was designed and prepared by the chemical introduction of DTPA and cyclic RGD to dextran, followed by the chelation of $\mathrm{Gd}^{3+}$ (Fig. 1). The extent of DTPA introduced to dextran could be changed by altering the amount of DTPA anhydride that was initially added. In this study, the dextran derivative with the maximum level of DTPA introduction was prepared for cyclic RGD conjugation. The amount of DTPA residues introduced was calculated to be 124 moles DTPA/mole dextran. The amount of cyclic RGD introduced was calculated to be 3.7 moles cyclic RGD/mole dextran. The amount of $\mathrm{Gd}^{3+}$ ion chelated was calculated to be 25 or $33 \mathrm{Gd}^{3+}$ molecules for one cyclic RGD-dextran-DTPA or dextran-DTPA molecule, respectively.
In vitro evaluation of contrast agent

Figure 2A shows fluorescent microscopic images for HUVEC after culturing with the cyclic RGD-dextran-DTPA or the dextran-DTPA. Cyclic RGD-dextran-DTPA was internalized into HUVEC to a greater extent than dextran-DTPA. $\mathrm{T}_{1}$-weighted images and $\mathrm{T}_{1}$ relaxivities for DTPA-Gd, dextran-DTPA-Gd, and cyclic RGD-dextran-DTPA-Gd with different concentrations are shown in Figure 2B. All contrast agents had lower $T_{1}$ relaxation times than DDW. The relaxivities increased in the order of DTPA-Gd, cyclic RGDdextran-DTPA-Gd, and dextran-DTPA-Gd.

\section{Evaluation of animal model}

Figure $3 \mathrm{~A}$ shows the blood perfusion image of mice hindlimb scanned by the laser-Doppler image analyzer. At 1 day after ischemia, blood perfusion of mice hindlimb ligated was drastically reduced. Partial recovery of blood perfusion was observed after 7 days. When the blood perfusion was analyzed quantitatively, it was found that the LDII gradually increased without any treatment (Fig. 3B). At 7 days after ischemia, angiogenesis was confirmed in the 
ischemic-angiogenic tissue of mice hindlimb, while less angiogenesis was observed in the normal region (Fig. 3C).

Figure 4 shows the expression images of integrin $\alpha_{v} \beta_{3}$ in the ischemic-angiogenic and normal tissues of mice with hindlimb ischemia created 7 days earlier. Both integrins $\alpha_{v}$ and $\beta_{3}$ were clearly detected in the ischemic-angiogenic region, while no signal was observed in the normal region.

\section{In vivo $M R$ imaging of ischemic-angiogenic region with cyclic RGD-dextran-DTPA-Gd}

Figures $5 \mathrm{~A}$ and $\mathrm{B}$ show $\mathrm{MR}$ images of mice hindlimb region before or after injection of dextran-DTPA-Gd or cyclic RGD-dextran-DTPA-Gd. From these pictures, the $\mathrm{T}_{1}$ signal intensity ratios in the ischemic-angiogenic region or normal region were plotted as a function of time after the injection (Fig. 5C). Cyclic RGD-dextran-DTPA-Gd showed high signal intensity in the ischemic-angiogenic region. On the other hand, the signal intensity ratio in the ischemic-angiogenic region for dextran-DTPA-Gd increased slightly and decreased to a normal region with time.

\section{Accumulation of cyclic RGD-dextran-DTPA in ischemic-angiogenic region}

Figure 6 shows the distribution percentages of cyclicRGD-dextran-DTPA or dextran-DTPA in the ischemicangiogenic or normal region of mice with hindlimb ischemia created 7 days earlier. From the MRI results (Fig. 5C), the distribution was evaluated $4 \mathrm{~h}$ after the injection of cyclicRGD-dextran-DTPA or dextran-DTPA. Irrespective of cyclic RGD introduction, the extents of dextran-DTPAs accumulated in the ischemic-angiogenic region were higher than those in the normal region. Furthermore, the percentage of cyclic RGD-dextran-DTPA distributed in the ischemic-

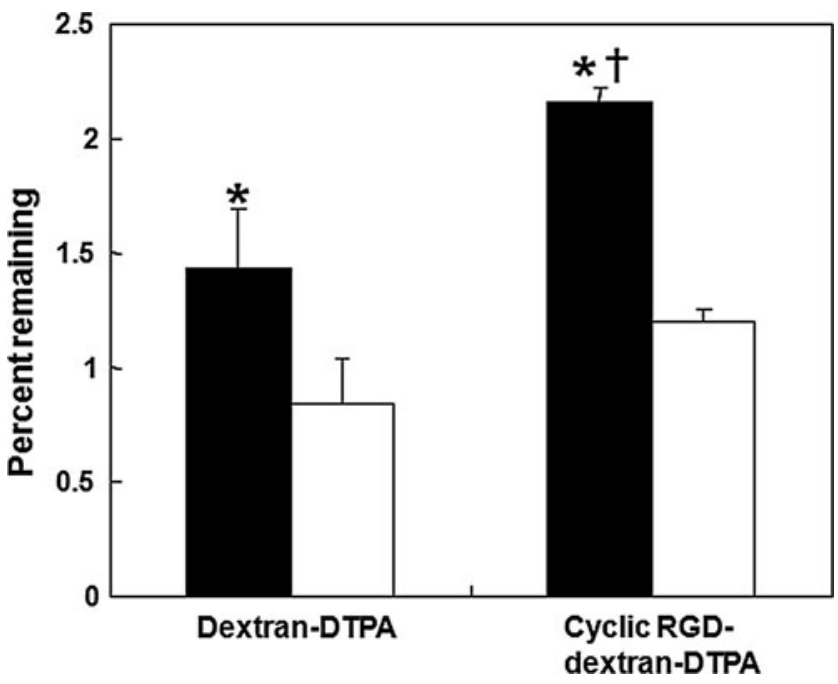

FIG. 6. Distribution of ${ }^{59} \mathrm{Fe}-$ labeled dextran-DTPA or cyclic RGD-dextran-DTPA in the ischemic-angiogenic ( $\square$ ) or normal $(\square)$ region of mice hindlimb $4 \mathrm{~h}$ after intravenous injection. Hindlimb ischemia (three mice each) was created 7 days before the injection. ${ }^{*} p<0.05$; significant against the percent remaining in normal region after the injection of the corresponding agent. ${ }^{\dagger} p<0.05$; significant against the percent remaining after the injection of dextran-DTPA-Fe. angiogenic region was significantly higher than that of dextran-DTPA.

\section{Discussion}

The goal of this study was to design and prepare a nanosized contrast agent for molecular imaging of therapeutic angiogenesis. The nano-sized contrast agent prepared in this study was composed of dextran, cyclic RGD, DTPA, and $\mathrm{Gd}^{3+}$. Dextran is a water-soluble and naturally occurring polysaccharide with low immunogenicity and a long history of clinical use as a plasma expander. ${ }^{49}$ Cyclic RGD peptide has a high affinity for integrin $\alpha_{\mathrm{v}} \beta_{3}$ of vascular endothelial cells expressed during proliferation or migration, ${ }^{43,44}$ and one type of cyclic RGD (EMD121974, Cilengitide) is used for clinical trial (phase II) as an inhibitor for tumor angiogenesis. ${ }^{50}$ The DTPA and $\mathrm{Gd}^{3+}$ are components of Magnevist ${ }^{\circledR}$ of an MRI-positive contrast agent clinically available. Since the dextran has a number of $\mathrm{OH}$ groups, the cyclic RGD as a ligand and DTPA as a chelator for imaging probe are expected to be simultaneously introduced to dextran. It has been reported that dextrans with molecular weights of 30,000 or higher are stable in the blood circulation after intravenous injection. ${ }^{51}$ Modification with a water-soluble polymer enables the ligands or imaging probes to be stably present in the blood circulation. $^{52}$ Therefore, it is highly expected that dextranbased contrast agents will enhance imaging efficacy. From the viewpoint of clinical application, dextran-based contrast agents (cyclic RGD-dextran-DTPA) are feasible, because each component (dextran, cyclic RGD, DTPA, and $\mathrm{Gd}^{3+}$ ) has been proved to be safe and used clinically, although the safety of cyclic RGD-dextran-DTPA complex needs to be carefully evaluated. Our conceptual study in rodents can easily be upscaled to a preclinical study with larger animals, such as swine.

The cyclic RGD-dextran-DTPA prepared was internalized into HUVEC to a greater extent than dextran-DTPA (Fig. 2A). It is likely that the affinity of cyclic RGD for the $\alpha_{v} \beta_{3}$ integrin expressed on the HUVEC surface enabled the cyclic RGD-dextran-DTPA to strongly interact with the cells, resulting in effective internalization in a receptor-mediated fashion. A lot of research has been conducted on the multimerization $^{53,54}$ or modification of cyclic RGD with nanosized carriers ${ }^{55-57}$ to enhance the affinity for integrin $\alpha_{v} \beta_{3}$. Although multiple cyclic RGD molecules could be introduced to dextran in this study, the cyclic RGD number introduced to dextran was not changed. Further investigations should be performed to optimize the number of cyclic RGD molecules and investigate the effects on the interaction strength with integrin $\alpha_{v} \beta_{3}$.

The conjugation of DTPA enabled dextran to chelate $\mathrm{Gd}^{3+}$ and shortened the relaxation time, while the $T_{1}$ relaxivities increased in the order of DTPA, cyclic RGD-dextran-DTPA, and dextran-DTPA at the same $\mathrm{Gd}^{3+}$ concentration (Fig. 2B). It is well recognized that the relaxivity is governed by the chemical structure of the compound chelating $\mathrm{Gd}^{3+}$, and the slow and restricted rotation of $\mathrm{Gd}^{3+}$ gives the compound high relaxivity. ${ }^{58}$ In the present study, cyclic RGD was chemically introduced to the carboxyl groups of DTPA for the chelation of $\mathrm{Gd}^{3+}$. Therefore, the chelating ability was slightly reduced, which caused a lower number of $\mathrm{Gd}^{3+}$ chelated with cyclic RGD-dextran-DTPA $\left(25 \mathrm{Gd}^{3+}\right)$ compared with dextran-DTPA $\left(33 \mathrm{Gd}^{3+}\right)$. It is conceivable that 
the extent of rotation restriction is increased in the order of DTPA, cyclic RGD-dextran-DTPA, and dextran-DTPA, which corresponds to the order of the relaxivities obtained. It is well known that DTPA has high chelation stability with many metal ions; this characteristic makes it possible to readily introduce other radioactive isotopes for scintigraphy, PET, and SPECT imaging.

The ischemic-angiogenic region could be clearly visualized on MRI after an intravenous injection of cyclic RGD-dextranDTPA-Gd (Fig. 5A). The signal profiles of dextran-DTPA-Gd and cyclic RGD-dextran-DTPA-Gd mostly agreed with the distribution behaviors conceivable from the result of radioisotope-based tracing analysis (Fig. 6). It was found by immunohistochemical staining that the $\alpha_{v} \beta_{3}$ integrin was expressed in the ischemic-angiogenic region of mice (Fig. 3C). In addition, it was also observed that the fluoresceinlabeled cyclic RGD-dextran-DTPA was co-localized in the integrin $\alpha_{\mathrm{v}} \beta_{3}$-positive region after an intravenous injection (data not shown). Taken together, it was clearly demonstrated that the affinity of cyclic RGD for the integrin $\alpha_{\mathrm{v}} \beta_{3}$ enabled the cyclic RGD-dextran-DTPA to selectively deliver to the ischemic-angiogenic region of mice with hindlimb ischemia. On the other hand, dextran-DTPA without cyclic RGD introduction was also slightly accumulated in the ischemic-angiogenic region. It is well recognized that inflammation is often induced, and the leakiness of blood vessels increases in ischemic-angiogenic regions. In addition, the lack of integrity in blood vessels formed during the initial steps of angiogenesis is involved in the high leakiness. It is, therefore, possible that dextran-DTPA was passively delivered to the ischemic-angiogenic region by extravasation from the blood vessel thereat, resulting in promoted accumulation. The signal ratios of dextran-DTPA and cyclic RGD-dextran-DTPA obtained by the radioisotope-based tracing analysis (Fig. 6) were higher than those by MRI $4 \mathrm{~h}$ after injection (Fig. 5C). This may be due to the fact that the sensitivity of ${ }^{59} \mathrm{Fe}(\gamma$ counter detection) is higher than that of $\mathrm{Gd}^{3+}$ (MRI detection).

Three points are remaining to be investigated for the practical use of cyclic RGD-dextran-DTPA-Gd. The first point is related to the preparation of multimodal imaging materials. Each imaging modality is based on quite different principles and has advantages and disadvantages. Generally, a single modality does not always correspond to all the requirements for diagnosis imaging. ${ }^{59}$ A combinational imaging system composed of different imaging modalities may compensate the deficiencies of single imaging modality. Currently, some prototypes of multimodal imaging system, including MRI-optical, NIRF-SPECT, PET-computed tomography, and SPECT-MRI, have been introduced. ${ }^{60-63}$ Further design and investigation of dextran-based multimodal imaging probes should be done to realize the idea of multimodal imaging. The second point is regarding the animal model of angiogenesis. In the present study, the natural healing after hindlimb ischemia in mice was used for the animal model of angiogenesis to remove the complicated factors involved in angiogenesis. It has been demonstrated that the controlled release of bioactive substances with gelatin hydrogel enables to promote and enhance the angiogenesis, which is clinically applied for the angiogenic therapy. ${ }^{6,64-66}$ Therefore, the combination of this technology with the contrast agent prepared in the present study will achieve more practical angiogenesis imaging. The final point is about the imaging timing of ischemic-angiogenic region. The expression of integrin $\alpha_{v} \beta_{3}$ was observed in the ischemicangiogenic region of mice with hindlimb ischemia created 7 days before (Fig. 3). Several research reports have indicated that the highest integrin $\alpha_{v} \beta_{3}$ expression was observed for mice with ischemia created 7 days earlier. ${ }^{41,67,68}$ Therefore, the mice with ischemia created 7 days earlier were used in the present study. However, it is practically important not only to detect the maximum angiogenesis but also to trace the integrin $\alpha_{v} \beta_{3}$ expression profiles. Imaging of integrin $\alpha_{v} \beta_{3}$ expression profiles will enable more detailed information to be obtained on the therapeutic effects and planning of additional therapies that are suitable for healing.

\section{Acknowledgments}

The authors would like to thank Ms. Sayaka Shibata and Ms. Misao Yoneyama (National Institute of Radiological Sciences, Japan) for their technical assistance. This research was partly supported by a Kakenhi grant from the Japanese Society for the Promotion of Science (JSPS) and the Ministry of Education, Culture, Sports, Science and Technology, Japan.

\section{Disclosure Statement}

No competing financial interests exist.

\section{References}

1. Tabata, Y., Hijikata, S., Muniruzzaman, M., and Ikada, Y. Neovascularization effect of biodegradable gelatin microspheres incorporating basic fibroblast growth factor. J Biomater Sci Polym Ed 10, 79, 1999.

2. Yamamoto, M., Takahashi, Y., and Tabata, Y. Controlled release by biodegradable hydrogels enhances the ectopic bone formation of bone morphogenetic protein. Biomaterials 24, 4375, 2003.

3. Itoh, M., Hiraoka, Y., Kataoka, K., Huh, N.H., Tabata, Y., and Okochi, $\mathrm{H}$. Novel collagen sponge reinforced with polyglycolic acid fiber produces robust, normal hair in murine hair reconstitution model. Tissue Eng 10, 818, 2004.

4. Kojima, K., Ignotz, R.A., Kushibiki, T., Tinsley, K.W., Tabata, Y., and Vacanti, C.A. Tissue-engineered trachea from sheep marrow stromal cells with transforming growth factor beta2 released from biodegradable microspheres in a nude rat recipient. J Thorac Cardiovasc Surg 128, 147, 2004.

5. Bajada, S., Mazakova, I., Richardson, J.B., and Ashammakhi, N. Updates on stem cells and their applications in regenerative medicine. J Tissue Eng Regen Med 2, 169, 2008.

6. Marui, A., Tabata, Y., Kojima, S., Yamamoto, M., Tambara, K., Nishina, T., Saji, Y., Inui, K., Hashida, T., Yokoyama, S., et al. A novel approach to therapeutic angiogenesis for patients with critical limb ischemia by sustained release of basic fibroblast growth factor using biodegradable gelatin hydrogel: an initial report of the phase I-IIa study. Circ J 71, 1181, 2007.

7. Lysiak-Drwal, K., Dominiak, M., Solski, L., Zywicka, B., Pielka, S., Konopka, T., and Gerber, H. Early histological evaluation of bone defect healing with and without guided bone regeneration techniques: experimental animal studies. Postepy Hig Med Dosw (Online) 62, 282, 2008.

8. Daglioglu, E., Dike, M.S., Kilinc, K., Erdogan, D., Take, G., Ergungor, F., Okay, O., and Biyikli, Z. Neuroprotective effect of melatonin on experimental peripheral nerve injury: 
an electron microscopic and biochemical study. Cent Eur Neurosurg 70, 109, 2009.

9. Fu, X.B., Sun, T.Z., Li, X.K., and Sheng, Z.Y. Morphological and distribution characteristics of sweat glands in hypertrophic scar and their possible effects on sweat gland regeneration. Chin Med J (Engl) 118, 186, 2005.

10. Rudin, M., and Weissleder, R. Molecular imaging in drug discovery and development. Nat Rev Drug Discov 2, 123, 2003.

11. Weissleder, R., and Mahmood, U. Molecular imaging. Radiology 219, 316, 2001.

12. Aoki, I., Takahashi, Y., Chuang, K.H., Silva, A.C., Igarashi, T., Tanaka, C., Childs, R.W., and Koretsky, A.P. Cell labeling for magnetic resonance imaging with the T1 agent manganese chloride. NMR Biomed 19, 50, 2006.

13. Rogers, W.J., Meyer, C.H., and Kramer, C.M. Technology insight: in vivo cell tracking by use of MRI. Nat Clin Pract 3, 554, 2006

14. Adonai, N., Nguyen, K.N., Walsh, J., Iyer, M., Toyokuni, T., Phelps, M.E., McCarthy, T., McCarthy, D.W., and Gambhir, S.S. Ex vivo cell labeling with 64Cu-pyruvaldehyde-bis(N4methylthiosemicarbazone) for imaging cell trafficking in mice with positron-emission tomography. Proc Natl Acad Sci U S A 99, 3030, 2002.

15. Tjuvajev, J.G., Doubrovin, M., Akhurst, T., Cai, S., Balatoni, J., Alauddin, M.M., Finn, R., Bornmann, W., Thaler, H., Conti, P.S., et al. Comparison of radiolabeled nucleoside probes (FIAU, FHBG, and FHPG) for PET imaging of HSV1tk gene expression. J Nucl Med 43, 1072, 2002.

16. Bennink, R.J., van Montfrans, C., de Jonge, W.J., de Bruin, K., van Deventer, S.J., and te Velde, A.A. Imaging of intestinal lymphocyte homing by means of pinhole SPECT in a TNBS colitis mouse model. Nucl Med Biol 31, 93, 2004.

17. Brenner, W., Aicher, A., Eckey, T., Massoudi, S., Zuhayra, M., Koehl, U., Heeschen, C., Kampen, W.U., Zeiher, A.M., Dimmeler, S., et al. 111In-labeled CD34+ hematopoietic progenitor cells in a rat myocardial infarction model. J Nucl Med 45, 512, 2004.

18. Kim, Y.H., Lee, D.S., Kang, J.H., Lee, Y.J., Chung, J.K., Roh, J.K., Kim, S.U., and Lee, M.C. Reversing the silencing of reporter sodium/iodide symporter transgene for stem cell tracking. J Nucl Med 46, 305, 2005.

19. Sato, A., and Klaunberg, B., Tolwani, R. In vivo bioluminescence imaging. Comp Med 54, 631, 2004.

20. Josserand, V., Texier-Nogues, I., Huber, P., Favrot, M.C., and Coll, J.L. Non-invasive in vivo optical imaging of the lacZ and luc gene expression in mice. Gene Ther 14, 1587, 2007.

21. Shah, K., and Weissleder, R. Molecular optical imaging: applications leading to the development of present day therapeutics. NeuroRx 2, 215, 2005.

22. Hoshino, A., Manabe, N., Fujioka, K., Suzuki, K., Yasuhara, M., and Yamamoto, K. Use of fluorescent quantum dot bioconjugates for cellular imaging of immune cells, cell organelle labeling, and nanomedicine: surface modification regulates biological function, including cytotoxicity. J Artif Organs 10, 149, 2007.

23. Jokerst, J.V., and Gambhir, S.S. Molecular imaging with theranostic nanoparticles. Acc Chem Res 44, 1050, 2011.

24. Villaraza, A.J., Bumb, A., and Brechbiel, M.W. Macromolecules, dendrimers, and nanomaterials in magnetic resonance imaging: the interplay between size, function, and pharmacokinetics. Chem Rev 110, 2921, 2010.

25. Dvorak, H.F. Angiogenesis: update 2005. J Thromb Haemost 3, 1835, 2005.
26. Wahlberg, E. Angiogenesis and arteriogenesis in limb ischemia. J Vasc Surg 38, 198, 2003.

27. Dobrucki, L.W., and Sinusas, A.J. Imaging angiogenesis. Curr Opin Biotechnol 18, 90, 2007.

28. Weis, S.M., and Cheresh, D.A. Tumor angiogenesis: molecular pathways and therapeutic targets. Nat Med 17, 1359, 2011.

29. Viola, R.J., Provenzale, J.M., Li, F., Li, C.Y., Yuan, H., Tashjian, J., and Dewhirst, M.W. In vivo bioluminescence imaging monitoring of hypoxia-inducible factor 1alpha, a promoter that protects cells, in response to chemotherapy. AJR Am J Roentgenol 191, 1779, 2008.

30. Kuchimaru, T., Kadonosono, T., Tanaka, S., Ushiki, T., Hiraoka, M., and Kizaka-Kondoh, S. In vivo imaging of HIFactive tumors by an oxygen-dependent degradation protein probe with an interchangeable labeling system. PLoS One 5, e15736, 2010.

31. Choe, Y.S., and Lee, K.H. Targeted in vivo imaging of angiogenesis: present status and perspectives. Curr Pharm Des 13, 17, 2007.

32. Cai, W., and Chen, X. Multimodality molecular imaging of tumor angiogenesis. J Nucl Med 49 Suppl 2, 113S, 2008.

33. Stollman, T.H., Ruers, T.J., Oyen, W.J., and Boerman, O.C. New targeted probes for radioimaging of angiogenesis. Methods (San Diego, Calif) 48, 188, 2009.

34. Li, W.P., and Anderson, C.J. Imaging matrix metalloproteinase expression in tumors. Q J Nucl Med 47, 201, 2003.

35. Scherer, R.L., McIntyre, J.O., and Matrisian, L.M. Imaging matrix metalloproteinases in cancer. Cancer Metastasis Rev 27, 679, 2008.

36. Beer, A.J., and Schwaiger, M. Imaging of integrin alphavbeta3 expression. Cancer Metastasis Rev 27, 631, 2008.

37. Zaccaro, L., Del Gatto, A., Pedone, C., and Saviano, M. Peptides for tumour therapy and diagnosis: current status and future directions. Curr Med Chem 16, 780, 2009.

38. Madeddu, P. Therapeutic angiogenesis and vasculogenesis for tissue regeneration. Exp Physiol 90, 315, 2005.

39. Meoli, D.F., Sadeghi, M.M., Krassilnikova, S., Bourke, B.N., Giordano, F.J., Dione, D.P., Su, H., Edwards, D.S., Liu, S., Harris, T.D., et al. Noninvasive imaging of myocardial angiogenesis following experimental myocardial infarction. J Clin Invest 113, 1684, 2004.

40. Leong-Poi, H., Christiansen, J., Heppner, P., Lewis, C.W., Klibanov, A.L., Kaul, S., and Lindner, J.R. Assessment of endogenous and therapeutic arteriogenesis by contrast ultrasound molecular imaging of integrin expression. Circulation 111, 3248, 2005.

41. Hua, J., Dobrucki, L.W., Sadeghi, M.M., Zhang, J., Bourke, B.N., Cavaliere, P., Song, J., Chow, C., Jahanshad, N., van Royen, N., et al. Noninvasive imaging of angiogenesis with a $99 \mathrm{mTc}$-labeled peptide targeted at alphavbeta3 integrin after murine hindlimb ischemia. Circulation 111, 3255, 2005.

42. Winter, P.M., Caruthers, S.D., Allen, J.S., Cai, K., Williams, T.A., Lanza, G.M., and Wickline, S.A. Molecular imaging of angiogenic therapy in peripheral vascular disease with alphanubeta3-integrin-targeted nanoparticles. Magn Reson Med 64, 369, 2010.

43. Rupp, P.A., and Little, C.D. Integrins in vascular development. Circ Res 89, 566, 2001.

44. Higuchi, T., Wester, H.J., and Schwaiger, M. Imaging of angiogenesis in cardiology. Eur J Nucl Med Mol Imaging 34 Suppl 1, S9, 2007. 
45. Hart, S.L., Knight, A.M., Harbottle, R.P., Mistry, A., Hunger, H.D., Cutler, D.F., Williamson, R., and Coutelle, C. Cell binding and internalization by filamentous phage displaying a cyclic Arg-Gly-Asp-containing peptide. J Biol Chem 269, 12468, 1994.

46. Schiffelers, R.M., Ansari, A., Xu, J., Zhou, Q., Tang, Q., Storm, G., Molema, G., Lu, P.Y., Scaria, P.V., and Woodle, M.C. Cancer siRNA therapy by tumor selective delivery with ligand-targeted sterically stabilized nanoparticle. Nucleic Acids Res 32, e149, 2004.

47. Habeeb, A.F. Determination of free amino groups in proteins by trinitrobenzenesulfonic acid. Anal Biochem 14, 328, 1966.

48. Belder, A.N.D., and Granath, K. Preparation and Properties of Fluorescein-Labeled Dextrans. Carbohyd Res 30, 375, 1973.

49. Klotz, U., and Kroemer, H. Clinical pharmacokinetic considerations in the use of plasma expanders. Clin Pharmacokinet 12, 123, 1987.

50. Alva, A., Slovin, S., Daignault, S., Carducci, M., Dipaola, R., Pienta, K., Agus, D., Cooney, K., Chen, A., Smith, D.C., et al. Phase II study of Cilengitide (EMD 121974, NSC 707544) in patients with non-metastatic castration resistant prostate cancer, NCI-6735. A study by the DOD/PCF prostate cancer clinical trials consortium. Invest New Drugs 30, 749, 2012.

51. Yamaoka, T., Tabata, Y., and Ikada, Y. Body distribution profile of polysaccharides after intravenous adrninistration. Drug Deliv 1, 75, 1993.

52. Duncan, R. The dawning era of polymer therapeutics. Nat Rev Drug Discov 2, 347, 2003.

53. Dijkgraaf, I., Rijnders, A.Y., Soede, A., Dechesne, A.C., van Esse, G.W., Brouwer, A.J., Corstens, F.H., Boerman, O.C., Rijkers, D.T., and Liskamp, R.M. Synthesis of DOTAconjugated multivalent cyclic-RGD peptide dendrimers via 1,3-dipolar cycloaddition and their biological evaluation: implications for tumor targeting and tumor imaging purposes. Org Biomol Chem 5, 935, 2007.

54. Liu, S. Radiolabeled cyclic RGD peptides as integrin alpha(v)beta(3)-targeted radiotracers: maximizing binding affinity via bivalency. Bioconjug Chem 20, 2199, 2009.

55. Montet, X., Funovics, M., Montet-Abou, K., Weissleder, R., and Josephson, L. Multivalent effects of RGD peptides obtained by nanoparticle display. J Med Chem 49, 6087, 2006.

56. Ke, T., Jeong, E.K., Wang, X., Feng, Y., Parker, D.L., and Lu, Z.R. RGD targeted poly(L-glutamic acid)-cystamine-(GdDO3A) conjugate for detecting angiogenesis biomarker alpha(v) beta3 integrin with MRT, mapping. Int J Nanomed 2, 191, 2007.

57. Lesniak, W.G., Kariapper, M.S., Nair, B.M., Tan, W., Hutson, A., Balogh, L.P., and Khan, M.K. Synthesis and characterization of PAMAM dendrimer-based multifunctional nanodevices for targeting alphavbeta3 integrins. Bioconjug Chem 18, 1148, 2007.

58. Terreno, E., Castelli, D.D., Viale, A., and Aime, S. Challenges for molecular magnetic resonance imaging. Chem Rev 110, 3019, 2010.
59. Massoud, T.F., and Gambhir, S.S. Molecular imaging in living subjects: seeing fundamental biological processes in a new light. Genes Dev 17, 545, 2003.

60. Chtourou, K., Maloul, M., Kallel, F., Charfedine, S., Hamza, F., and Guermazi, F. SPECT and MRI fusion for an extended bilateral osteonecrosis. Eur J Nucl Med Mol Imaging 35, 2343, 2008.

61. Ntziachristos, V., Yodh, A.G., Schnall, M., and Chance, B. Concurrent MRI and diffuse optical tomography of breast after indocyanine green enhancement. Proc Natl Acad Sci U S A 97, 2767, 2000.

62. Beyer, T., Townsend, D.W., Brun, T., Kinahan, P.E., Charron, M., Roddy, R., Jerin, J., Young, J., Byars, L., and Nutt, R. A combined PET/CT scanner for clinical oncology. J Nucl Med 41, 1369, 2000.

63. Veiseh, O., Sun, C., Gunn, J., Kohler, N., Gabikian, P., Lee, D., Bhattarai, N., Ellenbogen, R., Sze, R., Hallahan, A., et al. Optical and MRI multifunctional nanoprobe for targeting gliomas. Nano Lett 5, 1003, 2005.

64. Arai, Y., Fujita, M., Marui, A., Hirose, K., Sakaguchi, H., Ikeda, T., Tabata, Y., and Komeda, M. Combined treatment with sustained-release basic fibroblast growth factor and heparin enhances neovascularization in hypercholesterolemic mouse hindlimb ischemia. Circ J 71, 412, 2007.

65. Patel, Z.S., Ueda, H., Yamamoto, M., Tabata, Y., and Mikos, A.G. In vitro and in vivo release of vascular endothelial growth factor from gelatin microparticles and biodegradable composite scaffolds. Pharm Res 25, 2370, 2008.

66. Kimura, Y., and Tabata, Y. Controlled release of stromal-cellderived factor-1 from gelatin hydrogels enhances angiogenesis. J Biomater Sci Polym Ed 21, 37, 2010.

67. Couffinhal, T., Silver, M., Zheng, L.P., Kearney, M., Witzenbichler, B., and Isner, J.M. Mouse model of angiogenesis. Am J Pathol 152, 1667, 1998.

68. Almutairi, A., Rossin, R., Shokeen, M., Hagooly, A., Ananth, A., Capoccia, B., Guillaudeu, S., Abendschein, D., Anderson, C.J., Welch, M.J., et al. Biodegradable dendritic positronemitting nanoprobes for the noninvasive imaging of angiogenesis. Proc Natl Acad Sci U S A 106, 685, 2009.

Address correspondence to: Yasuhiko Tabata, Ph.D.

Department of Biomaterials Institute for Frontier Medical Sciences Kyoto University

53 Kawara-cho Shogoin

Sakyo-ku

Kyoto 606-8507

Japan

E-mail: yasuhiko@frontier.kyoto-u.ac.jp

Received: February 29, 2012

Accepted: July 17, 2012

Online Publication Date: September 10, 2012 